\title{
Modalities, Disciplinarity and Multiliteracies: the digital culture of higher education and the false promise of technological determinism
}

\author{
Jonathan J. FELIX ${ }^{1}$
}

\section{INTRODUCTION}

The COVID-19 pandemic is yet another world-changing event which has contributed to shifts in the social and material worlds human beings inhabit [1], as well as putting a spotlight on Modern attitudes and assumptions toward technologies and the contexts of their use. While both utopian and dystopian narratives of Modernity have been presented in popular texts, technology itself is commonly regarded as a necessary element to contemporary human life within this social and historic context. Some of the ideas which underpin Modernity as a time period involve discursive formations that emphasise the importance of rationality and the corresponding operationalisation of natural, human, and semiotic spheres towards greater measures of efficiency in advancing the multifaceted constitution of societies [2]-[5].

Modernity has been characterised by several scholars as a time period in world history marked by turbulent shifts in the social and material realities

\footnotetext{
${ }^{1}$ RMIT University, School of Communication and Design, Vietnam International and Comparative Education (ICE), Universiti Brunei Darussalam, Bandar Seri Begawan, Brunei DOI: 10.17932/EJOSS.2021.023/ejoss_v01i1002
} 
Modalities, Disciplinarity and Multiliteracies: the digital culture of higher education and the false promise of technological determinism

humans inhabit as a result of events, inventions, and occurrences predicated on particular ways of seeing the world [6]-[8]. While the invention of various technologies and their enduring impact is one of many key factors which shape interpersonal relations and broader social structures, natural and man-made events and occurrences such as the national independence of several countries from many years of colonial rule and diverse natural disasters are also examples of the makings of the Modern world [9], [10].

Popular discursive formations often feature the idea of technology as important to human advancement and also being an important aspect of living within the context of Modernity as evidenced by the several ways in which technology use is represented in popular texts such as Hollywood films, novels, advertising, and related social practices [11]-[13]. Like F. T. Marinetti and the Italian Futurists of the early 20th century, an affirmative sense of the utility, necessity, and to some degree excitement regarding technology is characteristic of Modern thinking [14], [15].

Nevertheless, the COVID-19 pandemic has led to arguably more losses than gains, given the negative impact of this event on human lives and livelihoods the world over [16]. As social institutions and the subjects which constitute them bear the fallout of this disruptive and historyaltering event, constituents of higher education institutions must now contend with reimaging the role and function such an entity within the discontinuities of Modernity and more recently, the post-COVID world [17]-[19]. 
The disruptive nature of the pandemic created a large-scale scramble to translate offline modes of instruction to online teaching [20]-[25]. As such, this massive shift in teaching and learning in general and higher education, in particular, has seen digital technologies used for teaching and learning offer convergent modalities for synchronous and asynchronous classroom delivery. However, despite the affordances of such technologies in providing interesting opportunities for teaching and learning, it has in no way has it definitively proven to be as emancipatory or revolutionary as some proponents of educational technology have argued before the pandemic occurred.

Without rehashing the realities and ramifications of this worldwide event, as this has already been documented by scholars interested or operating within perhaps almost every national and disciplinary context [26]-[30], in this article I would like to engage with the notion of the pandemic raising more pertinent issues regarding the pre-pandemic discourse on technology use, particularly in higher education, as having a 'salvific role in universally elevating education standards' [31, p. 2]. In previous work, I have both discussed and alluded to this utopian-type discourse, especially as an underlying technological determinism is often present with technology-based and technology-focused initiatives, particularly in higher education [32].

The forced experience of distance education mostly through online and mobile learning during the pandemic has foregrounded multimodal communication and the very socio-cultural nature of university learning and formal education more broadly. Moreover, I will comment on the 
Modalities, Disciplinarity and Multiliteracies: the digital culture of higher education and the false promise of technological determinism

implications of the social ecosystem of the university, the nature of disciplinarity and knowledge production, and the social production of teachers and learners taking into account the unstable and disruptive conditions brought about by the COVID-19 pandemic.

\section{Critiques of technological determinism in higher education}

Without relying on a dystopian logic, academics have argued against the misuse of technology, often ironically expressed by an optimistic naivety regarding its use as a signifier of Modernity [33]-[35]. Yet, it has been pointed out by scholars that such ideas have been rooted in the neoliberal orientation of higher education across the globe, which has been part of the drive towards the massification of the sector in which technology often believed to play a central role in development and assumed sustainability [36]-[40]. Kirkwood cautions against an uncritical, yet not unoptimistic view of technology in higher education in stating:

'University policy-makers, managers and teachers need to apply 'joinedup thinking' to technology use. This involves identifying and specifying the aims and purposes of using technology to support teaching and learning, bearing in mind that terms such as these are open to a variety of interpretations by those involved. Further, changes in any one organisational area are likely to have consequences in a number of others... Above all else, educational goals and purposes should take precedence over implicit technological determinism' [35 pp. 217-218].

Comparable arguments have been made by other scholars exploring the nature of higher education institutions as they function within a complex network of relationships between entities and actors in modern societies 
[41]-[43]. While Guthrie [42] reiterates the linkage between technology use in higher education and its role in shaping and accelerating knowledge production by highlighting challenges related to the 4th Industrial Revolution, a study by Mohammid \& Sinanan [43] draw attention to the social and cultural embeddedness in digital media use in higher education, as technology use in this context are appropriated and reappropriated in multiple ways by human agents. Yet, Perrotta [41] takes a more philosophical line of reasoning in pointing out the notion of underdetermination which refers to non-linear relationships between interdependent variables as a frame of reference for understanding technology use in higher education, but not as a means of positively predicting or engineering preferred outcomes.

What is especially pronounced here is the fact that multifaceted use of technology in higher education or perhaps any other context for that matter is one in which the elements of human agency and technological affordance need to be taken into account, in addition to a range of contextual factors notwithstanding other considerations which lie beyond the control of any kind of technology itself and those that use it. As such, underdetermination offers a means of avoiding the problematic of the false promise of technological determinism, but thinking in far broader terms than the capabilities or operationalisation of an invention used in a given context. 


\section{Negotiating the role of digital technology in higher education in the}

\section{1st century}

In keeping with this notion, the COVID-19 pandemic has in more ways than one highlighted and undermined utopian determinations of technology use in higher education, which was often posited by educational technologies before the pandemic and critiqued in with the same measure as it was defended by its proponents [44]-[47]. Yet before the advent of COVID-19, since the beginning of the 21 st century higher educational globally was undergoing a period of transition and negotiation in determining suitable strategies and approaches to optimise their operations within the contexts and constituents they serve [48]-[54].

However, COVID-19 has in some senses made questions of purpose and relevance even more urgent for higher education institutions, while at the same time putting a spotlight on questions of how the use of technologies or the lack thereof in a social ecosystem can and often does reflect, highlight, or exacerbate inequalities, divisions, and conflicts in the real world. As such, the biological nature of the pandemic, in terms of the global public health disaster which occurred, certainly presents the shortcomings of the technological in a very different light [55].

For example, some scholars have commented on the criticality needed to address how the internationalisation of higher education might be reimagined in the post-COVID world, by pointing towards the social conditions in which 'the consequences of inequality, insecurity, and political polarization' might flourish thereby limiting virtues of equity and sustainability [56]. Considering this, Taşç1 [56] has argued implicitly that 
technology presented a clearer view of problems than it did provide answers within the context of COVID-19.

A more explicit presentation of this argument takes into account the notion of 'intersectional inequalities' through a series of convergences and entanglements that make the idea of technological determinism untenable while at the same time acknowledging the importance of digital technology in higher education and other areas of modern societies across the globe [57]:

'...it is important not to let the overemphasis on 'digital solutions' disguise or divert from the more fundamental and deep-seated issues of segregation, division and hegemony...it is likely that digital technology will play an even more important role in shaping the post-pandemic world. It is critical to keep asking whether digital technology makes a better world [p. 5].

\section{Digital technologies, modalities and the multiliteracies of teaching and learning}

Now, as disciplinarity aids in understanding the complexity of the human experience, in the much the same way, modern technologies also mirror this idea, with digital technology use in higher education something that is used to engage with the various multiliteracies or the differing modalities of human communication - the visual, linguistic, aural, spatial, and gestural [58], [59]. At turn of the 20th century up until this time, scholars have been critiquing the very limited definition of 'literacy' as understood 
Modalities, Disciplinarity and Multiliteracies: the digital culture of higher education and the false promise of technological determinism

in relation to studies in education in general and higher education in particular.

Academics and researchers have highlighted the fact that the usefulness of the concept of literacy must be expanded to take into account not just the various modalities of human communication but also the ways in which individuals and groups navigate and negotiate their way through the complexities of modern societies [60]-[64]. As such, multiliteracies engage with communication and meaning-making in the interaction between human beings and the interconnected, mediated environments that are characteristic of late Modernity. These engagements take into account social, visual, technological, and cultural literacies which are not mutually exclusive domains of knowledge generation, dissemination, and consumption.

Hayles [64] has argued for greater engagement in academia with understanding how varying literacies work within this context, yet at the same time acknowledging the importance of digital technologies in shaping teaching and learning experiences in information-intensive environment(s)' (p. 61). In referencing several studies across the natural and social sciences, as a scholar of the humanities, Hayles [65] has also argued that digital technologies in higher education can be problematic insofar as it can it can create several issues including that of hyper attention, in which persons perform a highly stimulative, oscillating focus between numerous multiple points of reference, which presents cognitive challenges to the competing alternative of deep attention which requires more sustain attention. 
Nevertheless, while the affordance of digital technologies in higher education offers opportunity for multiliteracies in keeping with the varied modalities of human communication, Hayles [65] also observes that both hyper attention and deep attention are equality important as they can both be usefully employed in varying contexts which may be beneficial approaches to engagement depending on the task one is required to complete. It is worth pointing out that both hyper attention and deep attention often relate to engagement with the visual, linguistic, aural, and even gestural modalities, through digital technologies in higher education. However, of all these varied modes of engagement that can be offered to students via technological means, perhaps the spatial engagement may have been an undervalued modality, in terms of the implications of prepandemic foci, eclipsed by its more 'active' counterparts being the visual, aural, linguistic and gestural.

\section{The academy, disciplinarity, and the role of the spatial}

Alongside the priority placed by multiple constituents of the higher education sector globally on returning to college and university campuses to be part of the activities that occur within the physical infrastructures of these environments [66]-[69], there is little doubt the spatial modality is important as it relates to the performance of interrelated roles in the process and practice of teaching and learning. As such, meaning and identity are generated not only from the performative function of language in defining the actors within the higher education ecosystem [70], but also from physical environments and the interactions that take place in relation to these all the same. 
Furthermore, higher education institutions operate as key sites for social reproduction in modern societies, having a significant role in shaping the identities of modern subjects and in turn the character of the social worlds inhabited by individuals and groups [71]-[73]. Part of this identity formation relates to the performative use of language as I have argued in previous work [70], [74], [75], but also as it relates to how the roles of teaching, learning, and higher education institutions are conceptualised under the unstable and disruptive conditions brought about by the COVID19 pandemic.

As online instruction offers opportunities for both synchronous and asynchronous classroom delivery, the impact of COVID-19 influenced major largescale spatial restrictions, lockdowns, and social distancing all over the globe which in turn reinforced physical distance among the constituents of higher education institutions, leading to concerns regarding the sustainability of student and faculty motivation and attention, notwithstanding social and mental health concerns, despite the affordances of digital technologies [55], [76]. While the promise of Modernity involves the use of digital technologies in manipulating time and space in advantageous and efficient ways [4], [77], so far the forced use of these technologies have been suboptimal in terms of their employment out of sheer necessity and desperation, rather than through careful and highly calculated means.

Educators to date have critiqued the simplistic idea of "put(ting) lectures online' in response to the limitations presented by the COVID-19 pandemic, as a problematic approach to providing relevant, timely and 
quality educational experiences with any beneficial immediate or longterm benefit [77]. Within the context of the COVID-19 pandemic, research in higher education have spotlighted the importance of belonging as a major mechanism that promotes holistic well-being given the sociological functions of higher education institutions and their role in developing human capital in social, economic, cultural, and political senses [79].

Talarico [91] has stated that the significance of the spatial modality as it relates to the activities that occur within higher education institutions has not just to do with the cost-benefit of tuition fees, or psycho-social support, but with the sense of belonging or belongingness that is established when a community of practice congregates for interrelated reasons. Belonging or belongingness is defined as a biological and psycho-social need expressed in one's objective identification in addition to one's subjective feeling of being part of a broader, situated ecosystem of relations [80], [81].

This is idea of belonging is also present in the work of several education scholars [19], [78], [82]-[85], including that of Brown et al. [93] in which they investigate the entanglements of rural-based teenagers in middle school and the relationship between their social identities and the education institutions in which they study. What is of interest here in these instances of education-based scholarship, including many others, is how closely tied the idea of belonging is with not only disciplinarity, and the evolving role of the academy as a social institution, but how this is connected with the spatial, particularly in terms of materiality, in contrast 
Modalities, Disciplinarity and Multiliteracies: the digital culture of higher education and the false promise of technological determinism

to the actuality of virtual spaces offered through the affordances of digital technologies used within this context.

\section{CONCLUSION}

The COVID-19 pandemic saw innumerable higher education institutions across the globe make a dramatic shift to online learning with very uneven and perhaps precarious results overall [23], [24], [86]-[88]. However, as noted by Lee et al., [86] the pandemic presented 'limits to how much we can institutionalize and instruct student experiences at a distance' (p. 168). Such a sentiment also corresponds with previous studies which also highlight the importance of face-to-face teaching and learning and the nature of higher education ecosystems as social environments in which close interpersonal interactions are deemed as important [89]. Indeed, digital technology in higher education is hardly a magic bullet to address the issue of the sector in light of the realities of the post-COVID world, while it can be leveraged to ensure that some progress is made, as is the case with online teaching moving from a marginal pedagogical practice to a widespread social phenomenon.

Academics the world over have observed new vistas and frontiers that have been afforded through the pandemic, however, these point towards considerations for disciplinarity and the socialising role of human agents within the context of the academy, with far less emphasis on technology being a driver for change and more focus placed on how human agents negotiate technology use in a mindful way [78], [83], [90]-[92]. For example, researchers in India have expressed concerns regarding the teaching of agricultural sciences, which includes a highly practical range 
of subjects, in that digital technology use does not present a viable longterm solution for appropriate pedagogical measures [91]. This instance represents just one of several others where moving to online teaching exclusively or even in hybrid mode teaching can present practical issues in terms of how disciplinarity is practiced in addition to how teaching and learning may be conducted.

Scholars in various contexts have commented on the various entanglements that inform the development of the social identity formation process in education institutions and the corresponding capitals generated by individuals and groups [82], [93]-[96]. Yet these conceptualisations have not taken into account the role of digital technologies, and distance learning in particular, in shaping the interactions and identities of constituents who operate within the higher education ecosystem. While the far-reaching impacts of the pandemic may only be clearly seen retrospectively, it does add yet another layer of complexity to evolving function and role of higher education institutions across the globe. While the institutional reflexivity that is characteristic of late Modernity has led constituents to the higher education system to sector-wide reconsiderations of how tertiary-level study can the best possible social outcomes, there might no longer be the several concrete possibilities or futures to envisage, but rather ambiguous situations that require greater degrees of responsiveness to new information and realities that present itself as 'new normals'. 
Modalities, Disciplinarity and Multiliteracies: the digital culture of higher education and the false promise of technological determinism

\section{REFERENCES}

[1.]C. Bryce, P. Ring, S. Ashby, and J. K. Wardman, "Resilience in the face of uncertainty: early lessons from the COVID-19 pandemic," $J$. Risk Res., vol. 0, no. 0, pp. 1-8, 2020, doi: 10.1080/13669877.2020.1756379.

[2.]G. K. Bhambra, Rethinking Modernity: Postcolonialism and the Sociological Imagination. Chippenham and Eastbourne: Palgrave Macmillan, 2007.

[3.]B. Latour, An Inquiry into Modes of Existence: An Anthropology of the Moderns. Cambridge, Mass.: Harvard University Press, 2013.

[4.] M. O’Brien, S. Penna, and C. Hay, Theorising Modernity: Reflexivity, Environment and Identity in Giddens' Social Theory. Oxon: Routledge, 2013.

[5.]D. Gauntlett, "Giddens, Modernity, and Self-Identity," in Media, Gender and Identity: An Introduction, Wiltshire: Routledge, 2002.

[6.] A. Giddens, The Consequences of Modernity. Cambridge: Polity Press, 1996.

[7.]K. Gardner and F. Osella, "Migration, modernity and social transformation in South Asia: An overview," Contrib. to Indian Sociol., vol. 37, no. 1-2, pp. v-xxviii, 2003, doi: 10.1177/006996670303700101.

[8.] A. Mouzakitis, "Modernity and the Idea of Progress," Front. Sociol., vol. 2, no. March, pp. 1-11, 2017, doi: 10.3389/fsoc.2017.00003.

[9.]P. Duara, A Companion to Global Historical Thought. 2014.

[10.] J. O'Connor, Modernity and Postmodern Culture, vol. 5. 2000.

[11.] D. Holmes, Communication theory: Media, technology, society. 
London: SAGE Publications, 2005.

[12.] R. Foshay, The Digital Nexus: Identity, Agency, and Political Engagement. Edmonton: AU Press, 2016.

[13.] P. Bory, The Internet Myth: From the Internet Imaginary to Network Ideologies. 2020.

[14.] S. Redhead, We Have Never Been Postmodern: Theory at the Speed of Light. Edinburgh: Edinburgh University Press, 2011.

[15.] M. Rampley, Exploring Visual Culture: Definitions, Concepts, Contexts. Edinburgh: Edinburgh University Press, 2005.

[16.] L. M. Hite and K. S. McDonald, "Careers after COVID-19: challenges and changes," Hum. Resour. Dev. Int., vol. 23, no. 4, pp. 111, 2020, doi: 10.1080/13678868.2020.1779576.

[17.] M. Nandy, S. Lodh, and A. Tang, "Lessons from COVID-19 and a resilience model for higher education," Ind. High. Educ., 2020, doi: $10.1177 / 0950422220962696$.

[18.] R. C. Kalloo, B. Mitchell, and V. J. Kamalodeen, "Responding to the COVID-19 pandemic in Trinidad and Tobago: challenges and opportunities for teacher education," J. Educ. Teach., vol. 00, no. 00, pp. 1-11, 2020, doi: 10.1080/02607476.2020.1800407.

[19.] M. A. Peters et al., "Reimagining the new pedagogical possibilities for universities post-Covid-19: An EPAT Collective Project," Educ. Philos. Theory, vol. 0, no. 0, pp. 1-45, 2020, doi: 10.1080/00131857.2020.1777655.

[20.] J. Crawford, J. Butler-Hunderson, K Rudolph, M. B., M. Glowatz, R. Burton, and S. M. S. Lam, "View of COVID-19: 20 countries' higher education intra-period digital pedagogy responses," J. Appl. 
Modalities, Disciplinarity and Multiliteracies: the digital culture of higher education and the false promise of technological determinism

Learn. Teaching, vol. 3(1), no. 1, 2020, [Online]. Available: https://journals.sfu.ca/jalt/index.php/jalt/article/view/191/163.

[21.] M. P. A. Murphy, "COVID-19 and emergency eLearning: Consequences of the securitization of higher education for postpandemic pedagogy," Contemp. Secur. Policy, vol. 41, no. 3, pp. 492 505, 2020, doi: 10.1080/13523260.2020.1761749.

[22.] G. Korkmaz and Ç. Toraman, "Are We Ready for the PostCOVID-19 Educational Practice? An Investigation into What Educators Think as to Online Learning," Int. J. Technol. Educ. Sci., vol. 4, no. 4, pp. 293-309, 2020, doi: 10.46328/ijtes.v4i4.110.

[23.] O. N. Jacob, I. Abigeal, and A. E. Lydia, "Impact of COVID-19 on the Higher Institutions Development in Nigeria," Electron. Res. J. Soc. Sci. Humanit., vol. 2, no. I, pp. 168-172, 2020.

[24.] C. M. Toquero, "Challenges and Opportunities for Higher Education amid the COVID-19 Pandemic: The Philippine Context," Pedagog. Res., vol. 5, no. 4, p. em0063, 2020, doi: 10.29333/pr/7947. [25.] R. C. Kalloo, B. Mitchell, and V. J. Kamalodeen, "Responding to the COVID-19 pandemic in Trinidad and Tobago: challenges and opportunities for teacher education," J. Educ. Teach., vol. 46, no. 4, pp. 452-462, 2020, doi: 10.1080/02607476.2020.1800407.

[26.] K. MacMullin, P. Jerry, and K. Cook, "Psychotherapist experiences with telepsychotherapy: Pre COVID-19 lessons for a post COVID-19 world," J. Psychother. Integr., vol. 30, no. 2, pp. 248-264, 2020, doi: 10.1037/int0000213.

[27.] S. A. Zahra, "International entrepreneurship in the post Covid world," J. World Bus., vol. 56, no. 1, p. 101143, 2020, doi: 
10.1016/j.jwb.2020.101143.

[28.] A. M. Yohannes, "COPD patients in a COVID-19 society: depression and anxiety," Expert Review of Respiratory Medicine. pp. 1-3, 2021, doi: 10.1080/17476348.2020.1787835.

[29.] A. W. Kruglanski, E. Molinario, and E. P. Lemay, "Coping with COVID-19-induced threats to self," Gr. Process. Intergr. Relations, vol. 24, no. 2, pp. 284-289, 2021, doi: 10.1177/1368430220982074.

[30.] A. Marciano, "Dialogue Israel's Mass Surveillance during COVID-19: A Mised Opportunity," Surveill. Soc., vol. 19, no. 1, pp. 85-88, 2021, [Online]. Available: https://ojs.library.queensu.ca/index.php/surveillance-andsociety/index.

[31.] J. J. Felix, "Higher education in times of instability and disruption: Rethinking notions of values, value creation and instructional practices in Vietnam and beyond," Front. Commun., vol. 6, no. Cultural Changes in Instructional Practices Due to Covid-19, 2021, doi: 10.3389/fcomm.2021.647471.

[32.] J. J. Felix, "Doomed by Hope - Rethinking the Logic of Digital Technology Use in Higher Education,” 2019, [Online]. Available: https://youtu.be/VgfWL2IJR-Q.

[33.] A. Feenberg, "The Online Education Controversy and the Future of the University," Found. Sci., vol. 22, no. 2, pp. 363-371, 2015, doi: 10.1007/s10699-015-9444-9.

[34.] A. Kirkwood and L. Price, "Missing: evidence of a scholarly approach to teaching and learning with technology in higher education," Teach. High.Educ., vol. 18, no. 3, pp.327-337, 2013, doi: 
Modalities, Disciplinarity and Multiliteracies: the digital culture of higher education and the false promise of technological determinism

10.1080/13562517.2013.773419.

[35.] A. Kirkwood, "Teaching and learning with technology in higher education: blended and distance education needs 'joined-up thinking' rather than technological determinism," Open Learn., vol. 29, no. 3, pp. 206-221, 2014, doi: 10.1080/02680513.2015.1009884.

[36.] S. J. Ralston, "Higher Education's Microcredentialing Craze: a Postdigital-Deweyan Critique," Postdigital Sci. Educ., no. Gallagher 2018, 2020, doi: 10.1007/s42438-020-00121-8.

[37.] T. Elyas and M. Picard, "Critiquing of higher education policy in Saudi Arabia: Towards a new neoliberalism," Educ. Bus. Soc. Contemp. Middle East. Issues, vol. 6, no. 1, pp. 31-41, 2013, doi: 10.1108/17537981311314709.

[38.] H. T. Ngo, "'Standing between the flows': Interactions among Neoliberalism, Socialism and Confucianism in Vietnamese Higher Education Ha," in Higher education in market-oriented socialist Vietnam, L. H. Phan and N. B. Doan, Eds. Palgrave Macmillan, 2020, pp. 1-23.

[39.] [39] I. Roderick, "Recontextualising employability in the Active Learning Classroom," Discourse Stud. Cult. Polit. Educ., vol. 0, no. 0, pp. 1-17, 2019, doi: 10.1080/01596306.2019.1613020.

[40.] K. H. Mok and J. Jiang, "Massification of higher education and challenges for graduate employment and social mobility: East Asian experiences and sociological reflections," Int. J. Educ. Dev., vol. 63, pp. 44-51, 2018, doi: 10.1016/j.ijedudev.2017.02.003.

[41.] C. Perrotta, "Underdetermination, Assemblage Studies and Educational Technology: Rethinking Causality and Re-Energising 
Politics," J.New Approaches Educ.Res., vol. 9, no. 2, p. 43, 2021, doi: 10.7821/naer.2021.1.638.

[42.] K. M. Guthrie, "Challenges to Higher Education's Most Essential Purposes," Ithaka $S+R$, p. 12, 2019.

[43.] S. Mohammid and J. Sinanan, “'Why Didn’t You Just Google It?’: Digital Media and Informal Contexts for Learning," Caribb. J. Educ., vol. 41, no. 2, pp. 46-65, 2020.

[44.] P. Wheelan, "Education Technology: Is it All Hype with No Return?," EdSurge, 2016. https://www.edsurge.com/news/2016-0125-education-technology-is-it-all-hype-with-no-return (accessed Apr. $23,2019)$.

[45.] P. C. Herman, "Online learning is not the future," Inside Higher Ed, Jun. 10, 2020. https://www.insidehighered.com/digitallearning/views/2020/06/10/online-learning-not-future-highereducation-opinion (accessed Jan. 19, 2021).

[46.] H. E. Pence, "Artificial Intelligence in Higher Education: New Wine in Old Wineskins?," J. Educ. Technol. Syst., vol. 48, no. 1, pp. 5-13, 2019, doi: 10.1177/0047239519865577.

[47.] S. J. Ralston, "Postdigital Prospects for Blockchain-Disrupted Higher Education: Beyond the Theater, Memes and Marketing Hype," Postdigital Sci. Educ., vol. 2, no. 2, pp. 280-288, 2020, doi: 10.1007/s42438-019-00091-6.

[48.] V. Perselli, Education, Theory and Pedagogies of Change in a Global Landscape: Interdisciplinary Perspectives on the Role of Theory in Doctoral Research. London: Palgrave Macmillan, 2016. [49.] F. Findler, N. Schönherr, R. Lozano, D. Reider, and A. Martinuzzi, 
Modalities, Disciplinarity and Multiliteracies: the digital culture of higher education and the false promise of technological determinism

"The impacts of higher education institutions on sustainable development: A review and conceptualization," Int. J. Sustain. High. Educ., vol. 20, no. 1, pp. 23-38, 2019, doi: 10.1108/IJSHE-07-20170114 .

[50.] R. Vasilescu, C. Barna, M. Epure, and C. Baicu, "Developing university social responsibility: A model for the challenges of the new civil society," Procedia - Soc. Behav. Sci., vol. 2, no. 2, pp. 41774182, 2010, doi: 10.1016/j.sbspro.2010.03.660.

[51.] L. T. Mai and J. Hutnyk, "An intuition of innovative new institutions," Educ. Philos. Theory, vol. 52, no. 11, pp. 1120-1125, 2020, doi: 10.1080/00131857.2020.1757395.

[52.] A. J. Kezar, Understanding and Facilitating Organizational Change in the 21 st Century: Recent Research and Conceptualizations. San Francisco: Wiley, 2001.

[53.] N. Bowman, "Taking Responsibility : A Call for Higher Education ' s Engagement in a Society of Complex Global Challenges," Natl. Forum High. Educ. Public Good, pp. 1-104, 2006.

[54.] C. H. Nguyen and M. Shah, Quality assurance in vietnamese higher education: Policy and practice in the 21 st century, no. October. 2019.

[55.] N. K. Hayles, "Novel corona: Posthuman virus," Crit. Inq., vol. 47, no. S2, pp. S68-S72, 2021, doi: 10.1086/711439.

[56.] G. Taşçı, "The impact of COVID-19 on Higher Education: Rethinking internationalization behind the iceberg," Int. J. Curric. Instr., vol. 13, no. 1, pp. 522-526, 2021, [Online]. Available: http://ijci.wcci-international.org/index.php/IJCI/article/view/579/268. 
[57.] Y. Zheng and G. Walsham, "Inequality of what? An intersectional approach to digital inequality under Covid-19," Inf. Organ., vol. 31, no. 1, p. 100341, 2021, doi: 10.1016/j.infoandorg.2021.100341.

[58.] M. Kalantzis, B. Cope, and A. Harvey, "Assessing multiliteracies and the new basics," Int. J. Phytoremediation, vol. 21, no. 1, pp. 1526, 2003, doi: 10.1080/09695940301692.

[59.] B. Cope and M. Kalantzis, "From literacy to 'multiliteracies': Learning to mean in the new communications environment," English Stud. Africa, vol. 49, no. 1, 2006, doi: 10.1080/00138390608691342.

[60.] C. Westby, "Multiliteracies: The changing world of communication," Top. Lang. Disord., vol. 30, no. 1, pp. 64-71, 2010, doi: 10.1097/TLD.0b013e3181d0a0ab.

[61.] K. A. Mills, "Multiliteracies: Interrogating competing discourses," Lang. Educ., vol. 23, no. 2, pp. 103-116, 2009, doi: 10.1080/09500780802152762.

[62.] P. Smeyers, International Handbook of Philosophy of Education, Volume 1. Cham: Springer, 2018.

[63.] D. Fam, L. Neuhauser, and P. Gibbs, Transdisciplinary Theory, Practice and Education: The Art of Collaborative Research and Collective Learning. Cham: sp, 2018.

[64.] N. K. Hayles, How we think: Digital Media and Contemporary Technogenesis. Chicago: University of Chicago Press, 2012.

[65.] N. K. Hayles, "Hyper and Deep Attention: The Generational Divide in Cognitive Modes," Profession, vol. 2007, no. 1, pp. 187199, 2007, doi: 10.1632/prof.2007.2007.1.187.

[66.] G. Yamey and R. P. Walensky, "Covid-19: Re-opening 
Modalities, Disciplinarity and Multiliteracies: the digital culture of higher education and the false promise of technological determinism

universities is high risk," $B M J$, vol. 370, pp. 20-21, 2020, doi: 10.1136/bmj.m3365.

[67.] B. Caulfield, S. Browne, M. Mullin, S. Bowman, and C. Kelly, "Re-open our city and campus post-Covid: A case study of Trinity college Dublin, the University of Dublin," Case Stud. Transp. Policy, no. January, 2021, doi: 10.1016/j.cstp.2021.02.016.

[68.] J. Deshmukh, "Speculations on the post-pandemic university campus - a global inquiry," Archnet-IJAR, vol. 15, no. 1, pp. 131-147, 2021, doi: 10.1108/ARCH-10-2020-0245.

[69.] D. R. Smith, “ University campuses need people in them $\dagger$," EMBO Rep., no. March, pp. 1-2, 2021, doi: 10.15252/embr.202152591.

[70.] J. J. Felix, "Challenges in English as a Foreign Language (EFL) Teaching and Learning Research: Why Engagement With Theory Is Needed to Avoid Disciplinary Stagnation," in Stagnancy Issues and Change Initiatives for Global Education in the Digital Age, T. D. Neimann, J. J. Felix, S. Reeves, and E. Shliakhovchuk, Eds. Hershey: IGI Global, 2020, pp. 111-139.

[71.] M. Bunn, S. Threadgold, and P. J. Burke, "Class in Australian higher education: The university as a site of social reproduction," $J$. Sociol., vol. 56, no. 3, pp. 422-438, 2020, doi: $10.1177 / 1440783319851188$.

[72.] B. Green, "International higher education and global citizenship education: The rise of critical cosmopolitanism's 'personhood' in the age of covid-19," Knowl. Cult., vol. 8, no. 3, pp. 55-59, 2020, doi: $10.22381 / \mathrm{KC} 8320208$. 
[73.] J. E. Trinidad and E. N. P. Leviste, "Toward greater access and impact: Directions for a sociological understanding of Philippine higher education," Ind. High. Educ., 2020, doi: $10.1177 / 0950422220954062$.

[74.] J. J. Felix, "Autonomy and Motivation in Higher Education: Rethinking the Culture of Teaching and Learning," in Challenges and Opportunities in Global Approaches to Education, T. D. Neimann and U. M. Stelson, Eds. Hershey: IGI Global, 2019, pp. 164-177.

[75.] J. J. Felix, “Agency as Culture: Learner Autonomy and Motivation as Ordinary," in Proceedings of the International Conference on Language Teaching and Learning Today 2019: Autonomy and Motivation for Language Learning in the Interconnected World, 2019, no. April, [Online]. Available: http://ffl.hcmute.edu.vn/Resources/Docs/SubDomain/ffl/LTLT 2019/Booklet LTLT 2019.pdf.

[76.] S. Chen, "Interpersonal Communication Instruction During COVID-19: Challenges and Opportunities," Front. Commun., vol. 6, no. February, pp. 1-4, 2021, doi: 10.3389/fcomm.2021.652241.

[77.] P. Wagner, "Interpretations of modernity and the problem of world-making," Pap. Rev. Sociol., vol. 100, no. 3, p. 267, 2015, doi: 10.5565/rev/papers.2130.

[78.] B. Whalley, D. France, J. Park, A. Mauchline, and K. Welsh, "Towards flexible personalized learning and the future educational system in the fourth industrial revolution in the wake of Covid-19," High. Educ. Pedagog., vol. 6, no. 1, pp. 79-99, 2021, doi: 10.1080/23752696.2021.1883458. 
Modalities, Disciplinarity and Multiliteracies: the digital culture of higher education and the false promise of technological determinism

[79.] G. Arslan, "Loneliness, college belongingness, subjective vitality, and psychological adjustment during coronavirus pandemic: Development of the College Belongingness Questionnaire," J. Posit. Sch. Psychol., vol. 5, no. 1, pp. 1-15, 2020, [Online]. Available: https://journalppw.com/index.php/JPPW/article/view/240.

[80.] K.-A. Allen, M. L. Kern, C. S. Rozek, D. M. McInerney, and G. M. Slavich, "Belonging: a review of conceptual issues, an integrative framework, and directions for future research," Aust. J. Psychol., vol. 00, no. 00, pp. 1-16, 2021, doi: 10.1080/00049530.2021.1883409.

[81.] K. L. Gratz, M. T. Tull, J. R. Richmond, K. A. Edmonds, K. M. Scamaldo, and J. P. Rose, "Thwarted belongingness and perceived burdensomeness explain the associations of COVID-19 social and economic consequences to suicide risk," Suicide Life-Threatening Behav., vol. 50, no. 6, pp. 1140-1148, 2020, doi: 10.1111/sltb.12654.

[82.] L. H. Phan, Transnational Education Crossing "Asia" and "the West": Adjusted Desire, Transformative Mediocrity and Neo-colonial Disguise. Oxon: Routledge, 2017.

[83.] B. Bruggeman, J. Tondeur, K. Struyven, B. Pynoo, A. Garone, and S. Vanslambrouck, "Experts speaking: Crucial teacher attributes for implementing blended learning in higher education," Internet High. Educ., vol. 48, no. July 2020, p. 100772, 2021, doi: 10.1016/j.iheduc.2020.100772.

[84.] L. Rowan et al., "International students in the first years of senior secondary schooling in Australia: Longing for belonging," Int. J. Educ. Dev., vol. 81, no. November 2020, p. 102347, 2021, doi: 10.1016/j.ijedudev.2020.102347. 
[85.] J. C. K. Lee, Z. H. Wan, S. K. F. Hui, and P. Y. Ko, "More student trust, more self-regulation strategy? Exploring the effects of selfregulatory climate on self-regulated learning," J. Educ. Res., vol. 112, no. 4, pp. 463-472, 2019, doi: 10.1080/00220671.2018.1553840.

[86.] K. Lee, M. Fanguy, X. S. Lu, and B. Bligh, "Student learning during COVID-19: It was not as bad as we feared.," Distance Educ., vol. 42, no. 1, pp. 1-9, 2021, doi: 10.1080/01587919.2020.1869529.

[87.] W. Bao, "COVID -19 and online teaching in higher education: A case study of Peking University," Hum. Behav. Emerg. Technol., vol. 2, no. 2, pp. 113-115, 2020, doi: 10.1002/hbe2.191.

[88.] T. Trung, A. D. Hoang, T. T. Nguyen, V. H. Dinh, Y. C. Nguyen, and H. H. Pham, "Dataset of Vietnamese student's learning habits during COVID-19," Data Br., vol. 30, 2020, doi: 10.1016/j.dib.2020.105682.

[89.] S. Leaney and S. Mwale, "Campus closures and the devaluing of emplaced Higher Education: widening participation in neoliberal times," High.Educ., no. 0123456789, 2021, doi: 10.1007/s10734-02100696-6.

[90.] M. R. Kabir, A. Islam, and S. A. Deena, "Explaining the adoption of technology-based design of higher education during and after COVID 19 period from a developing country perspective," Interact. Des. Archit., no. 46, pp. 88-119, 2020.

[91.] T. Muthuprasad, S. Aiswarya, K. S. Aditya, and G. K. Jha, "Students' perception and preference for online education in India during COVID -19 pandemic," Soc. Sci. Humanit. Open, vol. 3, no. 1, p. 100101, 2021, doi: 10.1016/j.ssaho.2020.100101. 
[92.] D. Talarico, "How to address the wants and needs of your audience in this 'new normal,", Recruit. Retaining Adult Learn., vol. 23, no. 4, pp. 3-7, 2021, doi: 10.1002/nsr.30682.

[93.] S. Brown, P. Kelly, and S. K. Phillips, Belonging, Identity, Time and Young People's Engagement in the Middle Years of School. Cham: Palgrave Macmillan, 2020.

[94.] Y. L. Wong, “'Entitlement' and 'Legitimacy' as emotional capital: living out class through a critical educational failure by communitycollege students in Hong Kong," Stud. High. Educ., vol. 0, no. 0, pp. 1-14, 2020, doi: 10.1080/03075079.2020.1776244.

[95.] A. Voyer, "Of lads and ear'oles: School, work, and the microsociology of social reproduction," Ethnography, vol. 19, no. 4, pp. 565-576, 2018, doi: 10.1177/1466138118780153.

[96.] S. Duisenova, B. Kylyshbaeva, K. Avsydykova, and Y. Ishanov, "Sociological Analysis of Educational Strategies in the System of Higher Education in Kazakhstan," Sp. Cult. India, vol. 7, no. 4, pp. 181-193, 2020, doi: 10.20896/saci.v7i4.790. 